\title{
Identification of Lightning Stroke and Fault in the Travelling Wave Protection
}

\author{
Guibin Zou' ${ }^{1}$, Houlei Gao ${ }^{1}$, Wenbo Su${ }^{2}$, Dapeng Wang ${ }^{2}$ \\ ${ }^{1}$ School of Electrical Engineering, Shandong University; ${ }^{2}$ EPRI Shandong Electric Power Corporation, China. \\ Email: guibinzou@yahoo.cn; houleig@sdu.edu.cn \\ Received January $8^{\text {th }}, 2009$; revised January $31^{\text {st }}, 2009$; accepted February $11^{\text {th }}, 2009$.
}

\begin{abstract}
To resolve the impact of transient high frequency signals induced by lightning stroke on the travelling wave protection of transmission line, a novel identification algorithm is proposed. Using the characteristics of symmetric current waveform induced by lightning stroke without causing fault and that of asymmetric current waveform generated by fault within a very short time interval, the waveform of transient current above and below time-axes are integrated respectively. First, through comparing the relative ratio of them with threshold value, the primary criterion identifying fault and lightning stroke is constructed; Secondly, to improve the reliability of discrimination between lightning stroke with and without causing fault, according to the difference of them, the secondary criterion is also defined. The simulation results and analysis demonstrate that the proposed integral criterions are valid and correct.
\end{abstract}

Keywords: Transmission Line, Travelling Wave Based Protection, Lightning Stroke, Characteristic of Waveform, Criterion

\section{Introduction}

Travelling wave protection or transient component based protection is capable of achieving ultra high speed fault detection, and hence it has been focused by electrical engineers all over the world for tens of years. However, its reliability is always affecting application of protection in real power grid. The waveforms of transient current induced by lightning stroke and fault are similar, so lightning stroke is one of main influence factors which lead to low reliability of transient component based protection. Therefore, to improve the reliability of travelling wave protection or transient component based protection, it is a key to identify fault and disturbance of lightning stroke without causing fault correctly.

For these disturbances induced by lightning striking on transmission line, in recent years many specialists carried out a series of theoretical research, and obtained some useful results $[1,2,3,4,5,6,7]$. But most of previous identification principles used wavelet analysis tool to extract spectrum energies of different frequency bands of transient current signal, and according to energy differences, identification algorithms are implemented. Generally, these algorithms are complicated and difficult to use in practice. Different from the former identification methods, a novel integration based combined criterions are presented in this paper. Theoretical analysis and simulation results confirm that this identification algorithm is simple and has high reliability and sensitivity.

\section{Characteristic Analysis of Transient Signal}

From high voltage engineering we can know that lightning stroke is classified into two categories: one is direct lightning stroke and the other is indirect lightning stroke. Indirect lightning does not directly strike on transmission line and thus, the amplitude of over-voltage of line is low. For EHV/UHV transmission lines, since their towers are very high, it has not damage to them in general. But the probability of lightning striking directly on those lines is high [8]. When lightning directly strikes on transmission line, due to lightning current with high amplitude directly injects into the line, and hence serious over- voltage is caused. Direct lightning stroke is most serious high frequency disturbance to the transient component based protection, and it is focused on below.

When lightning stroke happens, the magnitude and waveform of lightning current are related to many factors, such as position and environment of transmission line, season and climate. So its amplitude and waveform are random. Although lightning currents have some big differences among different lightning strokes, the actual measured data demonstrate that they are all pulse waves with single pole. Moreover, its waveform is close to pair exponential curve as shown in Figure 1.

This waveform is expressed as in (1)

$$
i=I_{0}\left(e^{-\alpha t}-e^{-\beta t}\right)
$$




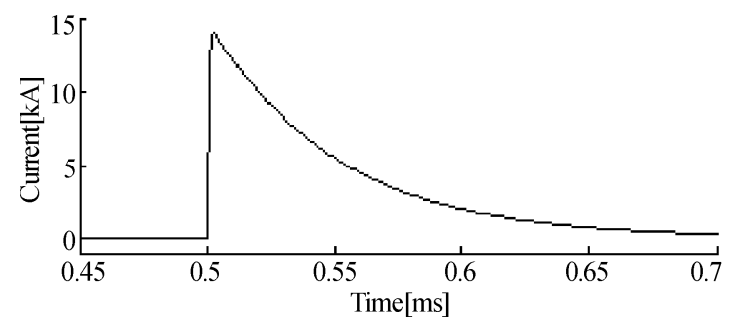

Figure 1. Waveform of lightning current

where $I_{0}$ is the peak value of lightning current; $\alpha$ and $\beta$ are coefficients of attenuation. IEC defined a normal pair exponential lightning wave using front time $t_{f}$ and time to half-value $t_{n}$. Time $t_{f}$ is about $1 \sim 4 u s$ and its mean value is $2.6 u s$. Time $t_{n}$ is about $20 \sim 90 u s$, which mean value is $43 u s$.

Using PSCAD/EMTDC, a model of $500 \mathrm{kV}$ power transmission system is constructed as shown in Figure 2. The line is frequency-dependent and balanced transposition. Tower is conventional horizontal structure, and on its top two shield lines are equipped. The line $M N$ is object researched and site of measurement $R$ lies in end $M$. Sampling frequency is $1 \mathrm{MHz}$. Stray capacitance of busbar is supposed as $\mathrm{C}_{\mathrm{S}}=0.01 \mathrm{uF}$. Supposing general fault and lighting stroke with or without causing fault occur at site $f$ away from end $M 50 \mathrm{~km}$, observing their characteristics of transient current waveforms respectively.

\subsection{Waveform Characteristic of Lightning Stroke without Causing Fault}

Lightning stroke causing fault has already resulted in line fault, so the relay should operate and cut the faulted line immediately; but lightning stroke without causing fault has not led to line fault actually, the relay should not operate. Therefore, the transient component based protection must correctly discriminate the waveform differences between lightning stroke without causing fault and general fault. There are two kinds of causes which lead to

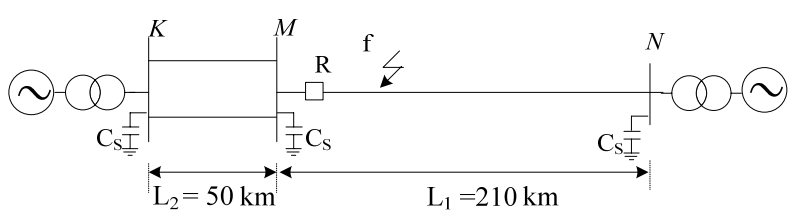

Figure 2. Model of $500 \mathrm{kV}$ power transmission system

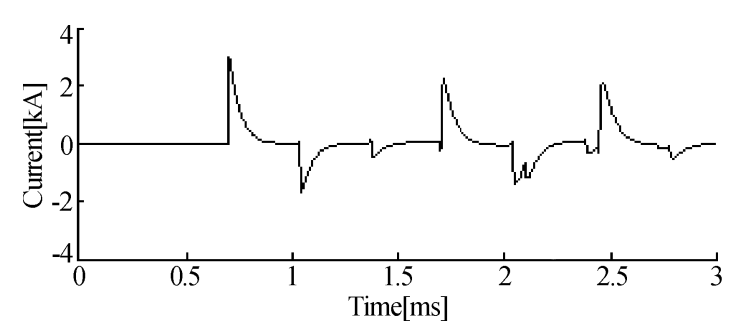

Figure 3. Aerial mode current of lightning stroke without causing fault lightning fault, one is shield failure and the other is back flashover. As mentioned in section 2, the towers of EHV/ UHV transmission lines are very high, the back flashover rarely happens, so in the following simulation we only consider lightning fault resulting from shield failure. Due to electromagnetic coupling exists among different phases, Clark transform is applied and aerial mode current is analyzed. Figure 3 shows aerial mode current waveform of transient component when tiny lightning stroke without causing fault occurs.

From Figure 3, it can be seen that wave peaks of current traveling wave induced by lightning stroke appear by turns above and below the time axes, and these wave peaks become attenuation gradually along time axes. Alternation frequency and attenuation speed are related to the length of line and structure of busbar. The polarity, wave shape and amplitude of the initial wave peak reflect the characteristics of lightning wave. The sequent wave peaks with same polarity are reflection wave of forward busbar and the wave peaks with opposite polar come from reflection wave of backward busbar. Since the actual transmission line is not lossless, during reflection and refraction of current wave, the wave peak continues to be attenuated and disappear in the end.

\subsection{Waveform Characteristic of Ordinary Line Fault}

Supposing a fault of phase A to ground and that of phase A to phase B occur on the line respectively. Fault earth resistance of single phase fault is $50 \Omega$ and fault inception angle is $60^{\circ}$. Figure 4 (a) and (b) show aerial mode current waveform of fault component respectively.

In Figure 4, it is obvious that the initial current signal contains much high frequency components owing to reflection and refraction of traveling wave. The top of initial wave peak is relative smooth close to a line, and its upward edge and downward edge are all very steep. In a very short time interval, the waveform generally lean to

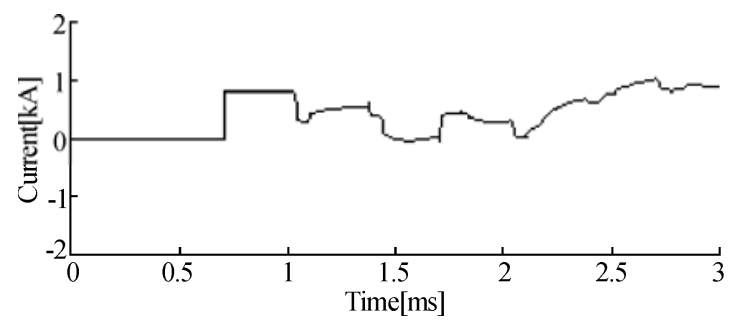

(a) Fault of phase A to ground

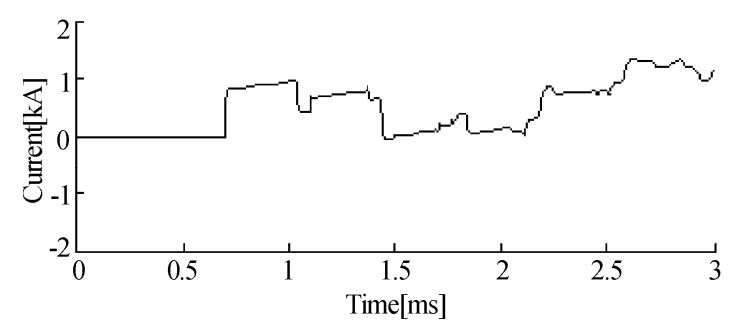

(b) Fault of phase $A$ to $B$

Figure 4. Aerial mode current waveform of fault 
one side of time axis, sometime waveform crosses zero, which is related to fault inception, configuration of busbar, et al. But as a whole, the wave shape shows a characteristic of flat variation.

\subsection{Waveform Characteristic of Lightning Stroke with Causing Fault}

Lightning strokes with causing fault actually include that lightning directly strikes on transmission line and tower, and further leads to insulation flash. For a same transmission line, the level enduring lightning of lighting striking on line is far lower than that of lightning striking on tower. Although their levels are different, the characteristics of current waveform induced by lightning stroke causing short-circuit are consistent, i.e. fault component of transient current is generated together by lightning current and power frequency extra voltage at fault site. In simulation, the amplitude of lightning current is $25 \mathrm{kA}$. Figure 5 shows aerial mode current waveform when lightning stroke with causing fault occurs.

Figure 5 shows that fault component current synchronously possesses these characteristics of two kind waveforms above mentioned: in the initial part of waveform, lightning wave makes a main effect, the positive and negative wave peaks appear alternately, and subsequent waveform displays some characteristics of short circuit fault. Within a short time interval, waveform leans to one side of time axis.

\section{Criterion of Identification}

According to above analysis, after transmission line is disturbed, within a very short time, the characteristics of transient current waveform are concluded as follows:

- Generally, the current waveform induced by lightning stroke without causing fault is symmetrical. The wave peaks of current traveling wave appear alternately above and below the time-axes, and peak values become attenuation gradually and until zero.

- As a whole, the transient current waveform generated by line fault shows a characteristic of smooth variation. In general, it leans to one side of time axis, sometimes crosses time axis.

- For the current waveform induced by lightning stroke causing fault, in its initial part the wave shape displays some characteristics of lightning wave, and after tens or hundreds of microseconds, which shows the characteristics of waveform of fault.

According to the characteristic differences of transient current waveforms generated by different disturbances, the integral criterions are defined. The transient current waveform above and below time axis are integrated respectively as follows:

$$
\begin{aligned}
& I_{+}=\int_{t_{0}}^{t_{0}+\tau} i_{+}(t) d t \\
& I_{-}=\int_{t_{0}}^{t_{0}+\tau}\left|i_{-}(t)\right| d t
\end{aligned}
$$

where $i_{+}(t)$ and $i_{-}(t)$ are fault component current above and below time axis respectively; $I_{+}$and $I_{-}$are integral values above and below time axis respectively within time-window $\tau ; t_{0}$ is inception moment when relay detects break of transient current. Owing to the symmetry of current waveform induced by lightning stroke without causing fault, $I_{+}$and $I_{-}$have a similar value; but for fault of line, the waveforms demonstrate they have a big difference. For lightning stroke causing fault, $I_{+}$and $I_{-}$are in between them above mentioned. To enlarge relative ratio value of $I_{+}$and $I_{-}$, and calculate their difference, two formulas are defined as follows:

$$
\begin{gathered}
\lambda=\frac{\max \left(I_{+}, I_{-}\right)-\min \left(I_{+}, I_{-}\right)}{\min \left(I_{+}, I_{-}\right)} \\
S=\left|I_{+}-I_{-}\right|
\end{gathered}
$$

where $\lambda$ is relative ratio value of $I_{+}$and $I_{-}$, and $S$ is their difference. In engineering calculation, discrete formulas of (2) and (3) are following:

$$
\begin{aligned}
& I_{+}=\sum_{k=n_{1}}^{n_{2}} i_{+}(k) \\
& I_{-}=\sum_{k=n_{1}}^{n_{2}} i_{-}(k)
\end{aligned}
$$

where $k, i(k)$ are sampling point and instantaneous value of fault component current respectively; $n_{1}$ is the initial sampling point where the break of transient current is detected. The number of points between $n_{1}$ and $n_{2}$ reflects a length of time-window. To improve speed of calculation and take waveform differences of transient current generated by different disturbances into account, the length $1 \mathrm{~ms}$ of time-window is adopted in simulation.

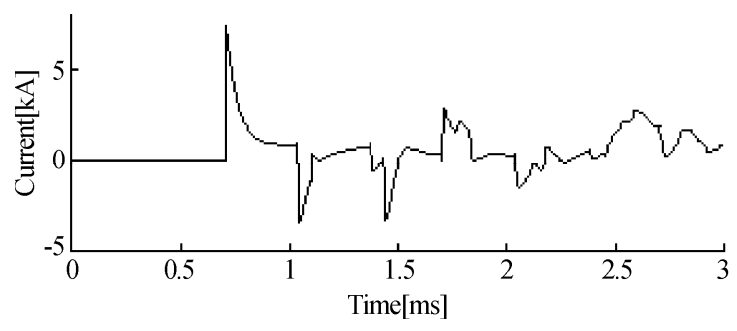

Figure 5. Waveform of lightning stroke causing fault

Table 1. Values of integration, $\lambda$ and $S$ after difference disturbances

\begin{tabular}{lcccc}
\hline & $I_{+} /(\mathrm{kA})$ & $I_{-} /(\mathrm{kA})$ & $\lambda$ & $S /(\mathrm{kA})$ \\
\hline $\begin{array}{l}\text { Lightning stroke without } \\
\text { causing fault }\end{array}$ & 172.2344 & 125.1907 & 0.3758 & 47.0437 \\
$\begin{array}{l}\text { Fault of phase A to ground } \\
\text { Fault of phase A to B }\end{array}$ & 455.6549 & 4.1076 & 109.9307 & 451.5474 \\
$\begin{array}{l}\text { Fault induced by lightning } \\
\text { stoke }\end{array}$ & 578.9154 & 2.7437 & 209.998 & 576.1717 \\
& 867.2476 & 292.8195 & 1.9617 & 574.4281 \\
\hline
\end{tabular}


For sampling frequency $1 \mathrm{MHz}$, the number of sampling points is 1000 . Table 1 shows simulation results of fault and lightning stroke with and without causing fault from measurement site $60 \mathrm{~km}$.

Data of Table 1 show: when lightning stroke without causing fault occurs, integral values $I_{+}$and $I_{\text {- }}$ are simiar, moreover values $\lambda$ and $S$ are all small; when fault occurs, the difference between values $I_{+}$and $I_{-}$is big, meanwhile values $\lambda$ and $S$ are all big; when a fault induced by lightning stroke occurs, the difference between values $I_{+}$and $I_{-}$is also big, and value $\lambda$ is in between that of short-circuit and that of lightning stroke without causing fault, but value $S$ is very big. Therefore, integral identification criterions are defined as follows:

- First, the primary criterion is defined. Threshold value $\lambda_{t}$ is set as 1 , if condition $\lambda>k_{1} \lambda_{t}$ ( $k_{1}$ is coefficient of reliability, its value is supposed as 1.2) is met, the disturbance of line is directly thought as fault and relay should operate rapidly.

- Secondly, to improve the reliability of identification of lightning stroke with and without causing fault, an additional criterion is defined. Threshold value $S_{t}$ is set as $100 \mathrm{kA}$ (its value is related to the sampling frequency and the length of time-window), if condition $\lambda_{t}<\lambda$ $<k_{1} \lambda_{t}$ is met, at the same time value $S$ meets condition $S>k_{1} S_{t}$, the disturbance of line is also determined as fault, relay should operate correctly. Otherwise, it is discriminated as lightning stroke without causing fault or other disturbance, and relay should not operate.

\section{Simulation and Analysis}

Based on analyzing waveform characteristics of fault component currents induced by various disturbances, the integral identification criterions are presented. But magnitude of transient current is affected by many factors, such as fault inception conditions, amplitude of lightning current, position of disturbance, configuration of busbar, et al., furthermore those factors possibly influence the reliability and sensitivity of integral criterions. Therefore using $500 \mathrm{kV}$ power transmission system model shown in Figure 2, the different disturbances are supposed in order to confirm validity of criterions.

\subsection{Simulation Results and Analysis for Different Faults}

Different faults of line will generate different fault component currents, and possibly affect the reliability of criterions. These factors include position of fault, fault inception angle, fault resistance and type of fault. According to those factors above mentioned, Table 2 listed corresponding simulation results.

From Table 2 we can see: for various faults from busbar $\mathrm{M} 60 \mathrm{~km}$, values $\lambda$ are far bigger than 1.2 ; for these faults with different inception angles, corresponding values $\lambda$ are also bigger than 1.2; for fault of close to measurement site (from busbar M $1 \mathrm{~km}$ ), remote-end fault (from busbar M 209km), corresponding values $\lambda$ are all higher than threshold value 1.2. These faults with little inception angle and big fault resistance would directly affect magnitude of transient current. But simulation results show: for two special types of faults, although the additional criterion $S$ is less than $100 \mathrm{kA}$, the primary criterion $\lambda$ is far higher than 1.2. Therefore, whatever conditions of fault are, the integral criterions can make a correct discrimination, moreover they have a very high reliability.

\subsection{Simulation Results and Analysis for Light- ning Stroke without Causing Fault}

It is well known that lightning stroke is random, and the magnitude of lightning current is related to many factors. Generally, for transmission line with shield line, when the magnitude of lightning current is less than a special value (such as $20 \mathrm{kA}$, related to configuration of line), lightning can strikes on line [9]. The position of lightning stroke and the magnitude of lightning wave will have an influence on magnitude of transient current. For various conditions of lightning stroke, Table 3 gives corresponding simulation results.

From Table 3 we can see: within a definite magnitude of lightning current, whichever phase lightning strikes on and wherever position of lightning stroke is, the corresponding values $\lambda$ are all less than 1.2 ; in general, the bigger magnitude of lightning current is, the stronger current traveling wave induced by lightning stroke is, moreover value $S$ may be bigger than $100 \mathrm{kA}$, but it hardly has any influence on value $\lambda$. Therefore, using the primary criterion, relay can easily discriminates the disturbance as lightning stroke without causing fault or other disturbance, and criterion has also a high reliability.

Table 2. Simulation results for different faults

\begin{tabular}{cccccccc}
\hline$T$ & $L /(\mathrm{km})$ & $\theta /\left(^{\circ}\right)$ & $R /(\Omega)$ & $I_{+} /(\mathrm{kA})$ & $I_{-} /(\mathrm{kA})$ & $\lambda$ & $S /(\mathrm{kA})$ \\
\hline $\mathrm{Ag}$ & 60 & 60 & 50 & 453.5737 & 4.1860 & 107.3542 & 449.3877 \\
$\mathrm{AC}$ & 60 & - & - & 605.1117 & 3.4286 & 175.4883 & 601.6830 \\
$\mathrm{BCg}$ & 60 & - & - & 188.6978 & 1.1684 & 160.4997 & 187.5294 \\
$\mathrm{Bg}$ & 60 & 0 & 50 & 0 & 54.2867 & $+\infty$ & 54.2867 \\
$\mathrm{Bg}$ & 60 & 90 & 50 & 11.9809 & 230.5606 & 18.2440 & 218.5797 \\
$\mathrm{Ag}$ & 1 & 60 & 50 & 519.8879 & 120.9268 & 3.2992 & 398.9611 \\
$\mathrm{Ag}$ & 209 & 60 & 50 & 561.9304 & 0 & $+\infty$ & 561.9304 \\
$\mathrm{Cg}$ & 60 & 45 & 0 & 0 & 187.8609 & $+\infty$ & 187.8609 \\
$\mathrm{Cg}$ & 60 & 45 & 500 & 0 & 47.9672 & $+\infty$ & 47.9672 \\
\hline
\end{tabular}

Note: $T$ - type of fault; $L$ - distance from busbar M; $\theta$ - fault inception angle; $R$ fault resistance.

Table 3. Simulation results for lightning stroke wihtout causing fault

\begin{tabular}{ccccccc}
\hline$P$ & $L /(\mathrm{km})$ & $I_{0} /(\mathrm{kA})$ & $I_{+} /(\mathrm{kA})$ & $I_{-} /(\mathrm{kA})$ & $\lambda$ & $S /(\mathrm{kA})$ \\
\hline $\mathrm{A}$ & 1 & 15 & 173.6715 & 126.2587 & 0.3755 & 47.4127 \\
$\mathrm{~A}$ & 10 & 15 & 173.6151 & 126.1870 & 0.3759 & 47.4281 \\
$\mathrm{~A}$ & 209 & 15 & 262.1816 & 269.3711 & 0.0274 & 7.1895 \\
$\mathrm{~B}$ & 60 & 15 & 167.5774 & 124.7613 & 0.3432 & 42.8161 \\
$\mathrm{C}$ & 60 & 3 & 45.0860 & 76.0670 & 0.6872 & 30.9810 \\
$\mathrm{C}$ & 60 & 10 & 158.1048 & 235.8736 & 0.4919 & 77.7688 \\
$\mathrm{C}$ & 60 & 20 & 319.8308 & 464.3272 & 0.4518 & 144.4964 \\
\hline
\end{tabular}

Note: $P$ - phase of lightning stroke; $I_{0}$ - amplitude of lightning current. 
Table 4. Simulation results for lightning stroke with causing fault

\begin{tabular}{ccccccc}
\hline$P$ & $L /(\mathrm{km})$ & $I_{0} /(\mathrm{kA})$ & $I_{+} /(\mathrm{kA})$ & $I-(\mathrm{kA})$ & $\lambda$ & $S /(\mathrm{kA})$ \\
\hline $\mathrm{A}$ & 1 & 25 & 1093.2 & 497.0937 & 1.1992 & 596.1001 \\
$\mathrm{~A}$ & 60 & 25 & 848.9874 & 292.8628 & 1.8989 & 556.1246 \\
$\mathrm{~A}$ & 209 & 25 & 986.5050 & 490.0102 & 1.0132 & 496.4948 \\
$\mathrm{~B}$ & 60 & 30 & 937.8617 & 363.1981 & 1.5822 & 574.6636 \\
$\mathrm{~A}$ & 60 & 30 & 937.8592 & 363.1872 & 1.5823 & 574.6720 \\
$\mathrm{~A}$ & 60 & 40 & 1122.0 & 510.3125 & 1.1985 & 611.6837 \\
\hline
\end{tabular}

\subsection{Simulation Results and Analysis for Light- ning Stroke Causing Fault}

For lightning stroke causing fault, to check its influence on integral criterions, in simulation adding magnitude of lightning current to $25 \mathrm{kA}$ and above, the insulation flash of line occurs, Table 4 lists simulation results.

Simulation results from Table 4 show: when lightning stroke causing fault occurs, values $\lambda$ are bigger than those of lightning stroke without causing faults but less than those of faults, and possibly be between $\lambda_{t}$ and $k_{1} \lambda_{t}$, but values $S$ are far bigger than $100 \mathrm{kA}$. Though low value $\lambda$ possibly lowers the sensitivity of primary criterion, a big value $S$ improves the sensitivity of additional criterion enormously. Therefore, using the primary and additional criterions together can improve the reliability of identification of lightning stroke without causing fault.

\section{Conclusions}

Correct identification of lightning stroke disturbance is a foundation for the reliability of travelling wave protection or transient component based protection. After analyzing the current waveform characteristics of fault and lightning strokes with and without causing fault in detail, the integral identification criterions are proposed. Within a short time-window, transient current waveforms above and below time axis are integrated respectively, further their relative ratio is defined as primary criterion and their difference is defined as additional criterion. Simulation results and analysis demonstrate: for ordinary fault and lightning stroke without leading to line fault, the primary criterion has a high reliability of identification; for lightning strokes with and without causing fault, sometimes the sensitivity of primary criterion is low, but additional criterion has a high sensitivity. Therefore, the proposed integral criterions can correctly identify general fault and disturbance of lightning stroke, moreover have a high reliability.

\section{REFERENCES}

[1] G. Wang, H. F. Li, J. C. Zhao, and M. Wu, "Identification of transients on transmission lines caused by direct lightning strokes based on multiresolution signal decomposition," Proceedings of the CSEE, Vol. 24, pp. 139-144, 2004.

[2] D. J. Si, H. C. Shu, X. Y. Chen, and J. L.Yu, "Study on characteristics and identification of transients on transmission lines caused by lightning stroke," Proceedings of the CSEE, Vol. 25, pp. 64-69, 2005.

[3] H. F. Li, G. Wang, and J. C. Zhao, "Study on characteristics and identification of transients on transmission lines caused by indirect lightning stroke," Proceedings of the CSEE, Vol. 24, pp. 114-119, 2004.

[4] J. D. Duan, B. H. Zhang, Z. G. Hao, and H. X. Ha, "Identification of lightning and fault in the EHV transmission line transient-based protection," Automation of Electric Power Systems, Vol. 28, pp. 30-35, 2004.

[5] X. L. Dong, Y. Z. Ge, and X. Z. Dong, "Effect of lightning on protection based on travelling wave," Proceedings of CESS, Vol. 22, pp. 74-78, 2002.

[6] J. F. Ren, J. D. Duan, and B. H. Zhang, "Identification of lightning disturbance in ultra-high-speed transmission line protection," The 2th IEEE/PES Transmission and Distribution Conference, Dalian, China, pp. 14-18, 2005.

[7] H. X. Ha and B. H. Zhang, "The study on identification of fault and lightning strokes in boundary protection for EHV transmission lines," Relay, Vol. 31, pp. 1-5, 2003.

[8] X. J. Wei and W. H. Wu, "The analysis of lightning protection for EHV and UHV transmission lines in Russia," High Voltage Engineering, Vol. 24, pp. 76-79, 1998.

[9] A. F. Imece, D. W. Durbak, H. Elahi, et al., "Modeling guidelines for fast front transients," IEEE Transactions on Power Delivery, 11, pp. 493-506, 1996. 